\title{
Improving the assessment of the environmental and economic efficiency of measures
}

\author{
Inna P. Bandurina ${ }^{1, *}$, Mikhail A. Bandurin ${ }^{1}$, and Alexander P. Bandurin ${ }^{2}$ \\ ${ }^{1}$ Kuban State Agrarian University named after I.T. Trubilin, 13/20-161, Kalinina str., Krasnodar, Russia \\ ${ }^{2}$ Don State Agrarian University, 46-56, Dubovskogo str. Novocherkassk, Russia
}

\begin{abstract}
The purpose of the study is to improve methods for improving the regulatory and methodological framework for assessing the environmental and economic effectiveness of land reclamation investment projects. The research methodology is based on the Monte Carlo method, which corresponds to international standards, the theory and algorithms of innovative methods for determining risks, as well as the ability to provide the user with information about the content of risk assessment operations and ensure that their preferences are taken into account in the calculation process. Currently, many tools have been developed for automating risk analysis procedures, including those performed by the Monte Carlo method, which are described in various studies with varying degrees of completeness. The analysis of priority methods of assessing the risks of achieving the projected economic indicators of project solutions is performed and the prospects of the simulation method for practical use in the field of land reclamation are shown. The results of the risk assessment of environmental and economic efficiency of anti-filtration coatings of hydraulic structures of irrigation systems performed by the Monte Carlo method in the environment of the Crystal Ball software product are presented, and the need to improve the reliability of the predicted results of the effectiveness of the designed measures is established. Future research is risk assessment of profitability of the designed activities promote the development of existing and formation of new theories to justify the feasibility of implementation of reclamation investment projects.
\end{abstract}

Keywords: environmental problems, monitoring, risk, projects, management

\section{Introduction}

The absence in the economic theory and practice of reclamation investment projects of a unified method of the effectiveness of project solutions that uniquely meets the user's multi-faceted requirements for analyzing the risk of investments has led to the priorities of heuristic models that use the skills of managers. Quantitative (analytical), qualitative and probabilistic methods of calculation have been developed to the maximum, each with its own advantages and disadvantages [1], without an explicit right of preference. The methods used for analyzing and accounting for investment project risks and comparative analysis of their functional capabilities based on research [2] are divided into: qualitative, assessing risk on a certain scale (high, medium, low risk level); quantitative, assessing risks by the numerical value of the indicator, and mixed.

The success of reducing the risk of reclamation investment projects is largely due to the methods used to analyze the effectiveness of the designed solutions, which significantly differ taking into account the variability (in space and time) of the project performance parameters that form quantitative risk indicators [3].

The need to analyze possible risks from the introduction of innovative production technologies already at the design stage is due to the need to exclude incompatibility of the introduced innovative technology with the conditions of use. Risks of investment in projects of the development of technological processes of production and management of activities are classified in theory according to many characteristics, among which the following are most often distinguished: possible result; source and period of risk occurrence [4].

Priority risk factors of reclamation investment projects include [5-7]:

- uncertainty of accounting for natural and economic conditions of the design object: farming systems; the intensity of agricultural production; completeness and accuracy of knowledge about the results of reclamation measures, capital investment standards in reclamation measures, conditions for the formation of fixed assets and working capital of production on reclaimed land, crop yields, costs of agricultural production, etc.;

- production and technological conditions associated with the possibility of non-fulfillment by the contractor implementing reclamation investment projects of its obligations to the customer; with the quality of reclamation work and requirements for technological processes of creation and operation, properties of building materials, etc. project characteristics that depend on the study of the

\footnotetext{
* Corresponding author: Chepuraib@gmail.com
} 
technical and technological environment for the implementation and functioning of the reclamation object;

- availability of financing, which characterizes the probability of the customer fulfilling financial obligations, the ability to attract borrowed funds, and the liquidity of agricultural products;

- investment climate that takes into account the depreciation of financial investments due to unforeseen changes in the political situation, legislation, etc. reasons caused by the procedures for institutionalizing the economy; unsuccessful investment of money in their own real investments;

- market conditions that determine the instability of the exchange rate, discount rates, and inflation indices.

The principal factor of profitable investment of capital is knowledge of the specifics of the implementation of specific investment projects and the use of effective innovative methods for calculating the effectiveness of planned activities [8]. The most general relationship between the probability of risk and the predicted return of an investor is reflected by a pattern: the higher the return on investment, the higher the risk of not achieving it; reducing the return increases the probability of no risk of investment [9].

\section{Figures and tables}

Assessment of the effectiveness of reclamation investment projects is characterized by a high level of risk of projected environmental and economic indicators due to the long, more than fifty-year period of implementation of project solutions, a large temporary benefit from investment to return. The success of reducing the risk of reclamation investment projects is largely due to the methods used to analyze the effectiveness of the designed solutions, which significantly differ taking into account the variability (in space and time) of the project performance parameters that form quantitative risk indicators.

\section{Equations and mathematics}

The object of the research is the Monte Carlo method, which complies with international standards, the theory and algorithms of innovative methods for determining risks, as well as the ability to provide the user with information about the content of risk assessment operations and ensure that his preferences are taken into account in the process of performing calculations.

The subject of the research is the analysis and calculations of the risk of economic efficiency of specific measures in the practice of the irrigation water management complex, to ensure high quality of strategic decisions and, as a result, the competitiveness and viability of the land reclamation sector.

The scientific novelty of the research lies in the development of the reliability of the predicted socio ecological and economic efficiency of reclamation investment projects. Simulation modeling or the Monte Carlo method is proposed as a promising method for monitoring the effectiveness of reclamation investment projects.

\section{Purpose of the Study}

The purpose of the study is to improve methods for improving the regulatory and methodological framework for assessing the environmental and economic effectiveness of land reclamation investment projects. The research methodology is based on the Monte Carlo method, which corresponds to international standards, the theory and algorithms of innovative methods for determining risks, as well as the ability to provide the user with information about the content of risk assessment operations and ensure that their preferences are taken into account in the calculation process.

\section{Research Methods}

The research methodology is based on the Monte Carlo method, which corresponds to international standards, the theory and algorithms of innovative methods for determining risks, as well as the ability to provide the user with information about the content of risk assessment operations and ensure that their preferences are taken into account in the calculation process. To date, many tools have been developed for automating risk analysis procedures, including those performed by the Monte Carlo method, which are described with varying degrees of completeness in various studies. Studying the degree of automation, the level of financial security, availability of experts etc, indicators of the system of evaluating the effectiveness of reclamation activities allowed establishing an initial period of the formation of the practice of risk assessment yields, the promise of using the tools of Crystal Ball, now owned by Oracle Corporation [10].

\section{Findings}

Qualitative analysis is performed to detect and characterize the likely risks of investment decisions, reveal the causes and conditions of their impact, determine the damage from expected risks and the cost of measures to reduce and /or eliminate it [11]). This approach usually precedes quantitative monitoring of the risk characteristics of investment decisions.

The generally recognized priority of quantitative accounting of risks and uncertainty of investment decisions is explained by the use of methods that increase the accuracy of calculating possible losses and minimize the subjectivity of the situation perception by the decision-maker [12].

The availability of many ways to control, account, and forecast of the risks of reclamation investment projects did not guarantee ease of evaluating the effectiveness of the latter in practice [9].

It connects with:

- wide range of requirements for taking into account the effectiveness of specific reclamation investment projects;

- insufficient attention to the specifics of reclamation investment projects when choosing the method of risk 
assessment, usually due to the preferences of the developer and the business entity;

- lack of a differentiated approach to assess the risk of reclamation investment projects depending on the stage of its life cycle;

- replacing the risk assessment with an assessment of the uncertainty of random events;

- lack of proper unification of certain methods of risk assessment;

- complexity of calculating and using projectspecific parameters in theoretical models.

At the same time, the priority of sensitivity, scenario and simulation modeling are traced.

The relative leadership of the statistical method of monitoring the risk of investment projects is explained by the accessibility of the applied theoretical approaches to the understanding of managers who form the decision and the simplicity of calculations [13]. The criteria of risk accounting and analysis are the average values of randomly changing performance indicators of investment decisions and their variation, which characterizes the degree of deviation of the predicted value from the average. The best solutions correspond to a smaller variation of the estimated parameter. The advantages of statistical risk analysis are often reduced by the lack of actual information about the probability distribution law of the estimated indicator, and replacing it, in most cases, with a normal one, which does not contribute to the accuracy of the result. Monitoring requires data from long-term series of observations of the parameters of the effectiveness of investment decisions, which is also not always achievable.

Project risks are divided into systematic or general risks that affect all forms of investment activity and all investment participants, and specific, internal risks that reflect the characteristics of a particular project. The priority of the specific risks of investments in the projects belongs to [14]:

- defects in design and estimate documentation, etc.;

- non-fulfillment of obligations by the contractor implementing reclamation investment projects;

- changing the goals and priorities of project participants in the development of activities;

- unreliability of knowledge about the financial situation and business reputation of project participants;

- attracting borrowed funds due to the customer's failure to fulfill its obligations to investors.

General risks include changes caused by changes in the external and internal economic environment, which determine a decrease in stock market rates, exchange rates, purchase prices for agricultural products, an increase in the discount rate, and other negative factors. Methods of monitoring the risks of investment decisions that are common in the economy and a comparative analysis of their functionality are given in the next section.

The simulation method or Monte Carlo method, successfully combining and improving the advantages of sensitivity and scenario analysis methods for assessing the risks of investment decisions, determines the impact of uncertainty on investment decisions based on simulation data, which provides the selection of key variables for the effectiveness of investment projects randomly by generating random numbers [15]. Investment performance indicators are recalculated using a given mathematical model that represents their dependence on random and deterministic components of project activities. The risk of investment decisions is calculated based on the probability of distribution of the performance indicator values.

The advantages of the method include compliance with the requirements of international standards, methodology and algorithms for determining risks, the ability of the user to understand the content of the risk procedures, which provides a sufficiently detailed description of the processes and required actions, and ensures that their preferences are taken into account in the calculation process.

The complexity and labour capacity of performing the necessary calculations, which become obsolete with the development of information technologies, initially served as a deterrent to the introduction of the method of risk assessment of investment decisions in practice.

The advantages of the method of parameter variation (sensitivity analysis) include high theoretical validity, simplicity of calculations, the ability to visualize the result, and so, on properties. The disadvantages of the method are that it is impossible to account for the correlation between risk factors and obtain a probability distribution of risk estimates. The profitability of reclamation investment projects is most dependent on the discount rate. This is due to the exponential dependence of the projected cost of money on this factor, with a fixed discount rate; priority is given to purchase prices and agricultural production costs [16].

Scenario analysis, being a logical development of sensitivity analysis, increases the accuracy of calculations and, consequently, the resulting data, and provides for accounting for the variability of events for the estimated performance indicators of the project. The assessment is based on the optimistic, pessimistic, and most likely scenarios of simultaneously changing factors, under which the estimated performance indicators of the project are calculated. The risk is assessed by the deviation of the weighted average of the values of the optimistic, pessimistic and optimal options for the profitability of reclamation investment projects from the value of the base option. Based on the difference between the planned and forecast values of investment performance indicators in the project, conclusions are drawn about the risk of investment decisions and/or the presence of additional risk factors in the project to be taken into account. The disadvantages of the method include the lack of formal methods for forming the boundaries of scenarios and estimating the values of variables for them [17].

The advantages of the Monte Carlo method are compliance with international standards, the theory and algorithms of innovative methods for determining risks, providing the user with information about the content of risk assessment operations and ensuring that their preferences are taken into account in the calculation process [18]. 
The widespread use of the Monte Carlo method in the practice of monitoring the risk of project decisions was initially hindered by the complexity and complexity of calculations, which, with the development of information technologies, lose their significance.

The risk assessment of investments in the planned measures of anti filtration protection of water supply structures and irrigation systems is carried out as part of the following procedures and their sequence:

- development of an analytical expression that characterizes the relationship between the desired indicator of project profitability and the source data presented by factors that affect the change in the result;

- setting the distribution function for the model's input indicators;

- computer simulation that involves generating random values of source factors;

- formation of the model distribution function, and calculation of project profitability risk parameters;

- analysis of the final results.

To date, many tools have been developed for automating risk analysis procedures, including those performed by the Monte Carlo method, which are described with varying degrees of completeness in studies [19].

Based on the results of the analysis of existing approaches to the development of a system for evaluating the effectiveness of reclamation investment projects, the Crystal Ball toolkit developed by Oracle Corporation is proposed to develop the practice of analyzing and accounting for the risks of their profitability [20].

In this publication, the procedures of analyzing and accounting of the risk of environmental and economic efficiency of reclamation investment projects using the simulation method (Monte Carlo method) are presented by the example of an existing project aimed at improving the sustainability and reducing unproductive irrigation water waste, developed and implemented by employees of the JSC "Institute of safety of hydraulic structures".

As the effect (result) of reclamation investment projects, the prevented damage from the elimination of unauthorized irrigation water costs was taken, and the cost of creating and operating a protective device was taken as the cost (table 1).

The extension of the period of effective operation of irrigation system structures is provided by the device of anti-filtration two-layer coating of irrigation channels made of geotextile material with soil filler [21].

The discounted balance of the incremental flow calculated for the standard period of operation of the protective complex of a hydraulic structure is positive and amounts to 210.6 thousand rubles, the payback period of total capital investments based on the increase in discounted net income does not exceed one and a half years.

The risk of reclamation investment projects was calculated based on the probability of not achieving the planned return if the deviation from the predicted values of the prevented damage from reducing water losses, the cost of installing and operating a protective device, and the discount rate. These factors are significant when calculating the profitability of reclamation investment projects [22]. The calculations were performed using the commercial software product Crystal Ball in the Excel program.

Table 1. Data for calculating the effectiveness of anti-filtration protection

\begin{tabular}{|c|c|c|c|}
\hline \multirow{2}{*}{ Title } & \multirow{2}{*}{$\begin{array}{c}\text { Unit of } \\
\text { measurement }\end{array}$} & $\begin{array}{c}\text { Before } \\
\text { repair }\end{array}$ & $\begin{array}{c}\text { After } \\
\text { repair }\end{array}$ \\
\cline { 3 - 4 } & Reduction of \\
water losses * & $\begin{array}{c}\text { th. m3/km per } \\
\text { year }\end{array}$ & - & 92.5 \\
\hline $\begin{array}{c}\text { Unit costs of } \\
\text { water supply* }\end{array}$ & rub./ m3 & 0.12 & 0.12 \\
\hline $\begin{array}{c}\text { Prevented } \\
\text { damage from } \\
\text { reducing } \\
\text { irrigation water } \\
\text { losses }\end{array}$ & $\begin{array}{c}\text { th. rub./ per } \\
\text { year }\end{array}$ & - & 11.1 \\
\hline $\begin{array}{c}\text { Cost of the } \\
\text { protective } \\
\text { device }\end{array}$ & th. rub./km & - & 50 \\
\hline $\begin{array}{c}\text { Operating costs } \\
\text { of anti-filtration } \\
\text { protection }\end{array}$ & $\begin{array}{c}\text { th. rub./km per } \\
\text { year }\end{array}$ & - & $1.0 *$ \\
\hline $\begin{array}{c}\text { Service life of } \\
\text { the protective } \\
\text { device }\end{array}$ & year & 30 & 30 \\
\hline $\begin{array}{c}\text { Discount rate } \\
\text { Discon }\end{array}$ & \% & 8 \\
\hline
\end{tabular}

Risk assessment of reclamation investment projects required:

- development of analytical dependence of the project's economic efficiency on the factors that determine it;

- formation of distribution functions for the dependence of the economic efficiency of reclamation investment projects and its determining factors;

- computer generated random values of effective analytical dependence factors;

- calculation of risk parameters of profitability of reclamation investment projects [23];

- analysis of the final results.

The probability of the predicted values of parameters and the dependence of the profitability of reclamation investment projects is characterized by normal distribution functions, which are described by knowing the average value and the standard deviation from the average.

Thus, the analysis and calculations of the risk of economic efficiency of specific measures in the practice of irrigation water management clearly showed the need for a comprehensive and in-depth assessment of the effectiveness of planned measures. This will benefit the resurgent innovation activity, ensuring high quality of strategic decisions and, as a result, the competitiveness and viability of the land reclamation sector.

The results of calculating the parameters of distribution functions for key factors of dependence on the profitability of reclamation investment projects are presented in Table 2. 
Table 2. Parameters of distribution functions

\begin{tabular}{|c|c|c|c|}
\hline \multirow{2}{*}{$\begin{array}{c}\text { Factor } \\
\text { Reduction of } \\
\text { water losses, th. } \\
\mathbf{m}^{3} / \mathrm{km} \text { per year }\end{array}$} & \multirow{2}{*}{$\begin{array}{l}\text { Limits of } 90 \% \\
\text { confidential } \\
\text { interval } \\
\text { from } 70 \text { to } 115 \\
\end{array}$} & \multicolumn{2}{|c|}{ Average value } \\
\hline & & 92.5 & 13.68 \\
\hline $\begin{array}{l}\text { Specific costs to } \\
\text { water supply, } \\
\text { rub. } / \mathrm{m}^{3}\end{array}$ & from 0,12 to 0.20 & 0.16 & 0.024 \\
\hline $\begin{array}{l}\text { Costs for protective } \\
\text { unit, th. rub./km }\end{array}$ & from 65 to 45 & 55 & 6.069 \\
\hline $\begin{array}{l}\text { Operating costs, } \\
\text { th.rubles / km per } \\
\text { year }\end{array}$ & from 1.3 to 0.9 & 1.1 & 0.122 \\
\hline $\begin{array}{l}\text { Coefficient of } \\
\text { discount } \%\end{array}$ & from 0.29 to 0.51 & 0.40 & 0.092 \\
\hline
\end{tabular}

This requires increased attention of the operations service to compliance with the rules for implementing production processes and technologies regulated by the project, as well as to the market environment, which determines the variability of the result in the first place. Account of these factors is also necessary to determine the scope of implementation of the proposed technological improvements. The low risk of the effectiveness of reclamation investment projects is indicated by the absolute probability of a positive value of the effectiveness of the investment project.

But at the same time, it is obvious that the probability of profitability in the amount of 210.6 thousand rubles, declared in the project, does not reach $10 \%$, which is lower than the average value. Therefore, it is necessary to pay more attention to the implementation of production processes and technologies regulated by the project, as well as to market conditions as priority factors that determine the variability of the result.

\section{Conclusion}

Improving the reliability of the predicted socioecological and economic performance of reclamation investment projects requires improving the regulatory framework for assessing the risk of not achieving the predicted result. As a promising method for monitoring the effectiveness of reclamation investment projects, we propose simulation modeling or the Monte Carlo method, which has been successfully tested as part of these studies.

\section{References}

1. L.V. Kireicheva, O.B. Khokhlova. Elemental composition of different fractions from the sapropel organic matter. Euras. Soil Sci., 33(9), 947-949 (2000)

2. L.V. Kireicheva, O.A. Zakharova. The effect of cyclic irrigation with wastewater on the properties of gray forest soils. Euras. Soil Sci., 35(9), 990-995 (2002)

3. N. Fen, D.B. Kozlov, I.S. Rumyantsev. Hydraulic studies of stepped spillways of various design. Pow. Technol. and Eng., 49(5), 337-344 (2016)
4. V.I. Olgarenko, G.V. Olgarenko, I.V. Olgarenko. A method of integral efficiency evaluation of water use on irrigation systems. Int. Multidiscipl. Sci., GeoConf. SGEM, 18(3.1), 3-9 (2018)

5. N.F. Ryzhko, F.K. Abdrazakov, S.N. Ryzhko, S.V. Botov. The increase of qualitative indicators during watering with multiple support sprinklers. J. of Fund. and Appl. Sci., 10(6S), 1482-1497 (2018)

6. D.V. Kozlov. A linear dynamic model for calculating the transverse oscillation of free-floating ice cover. Water Res., 28(2), 215-219 (2001)

7. V.I. Olgarenko, I.V. Olgarenko, V.I. Selyukov. Computer technology of planning water use in irrigation systems. Bull. of the Rus. Acad. of Agricult. Sci., 4, 12-15 (2012)

8. I.P. Kruzhilin, M.A. Ganiev, V.V. Melikhov, K.A. Rodin, N.N. Dubenok, A.S. Ovchinnikov, S.D. Fomin, N.M. Abdou. Mode of rice drip irrigation. ARPN J. of Eng. and Appl. Sci., 12(24), 7118-7123 (2017)

9. D.V. Kozlov, A.N. Nasonov, I.M. Zhogin, I.V. Tsvetkov. Multifractal principles of aquatic ecosystem development control by algacenosis correction. Water Res., 44(2), 259-266 (2017)

10. M.A. Bandurin, V.A Volosukhin,. A.V. Mikheev, Y.V. Volosukhin, V.V. Vanzha. Finite-element simulation of possible natural disasters on landfall dams with changes in climate and seismic conditions taken into account. J. of Phys. Conf. Ser., 1015, 032011 (2018)

11. B.P. Chesnokov, O.V. Naumova, V.A. Strelnikov, F.K. Abdrazakov, B.A. Tronin. Polyethylene production from granules using high voltage. Int. J. of Appl. Eng. Res., 11, 2140-2144 (2016)

12. V.I. Olgarenko, G.V. Olgarenko, I.V. Olgarenko. Integrated assessment of the technical level of the irrigation and drainage systems. Meliorat. and water manag., 6, 8-11 (2013)

13. F.K. Abdrazakov, N.F. Ryzhko, S.N. Ryzhko, S.A. Horin, S.V. Botov. Electricity consumption decrease at pump stations during watering by multisupport sprinkling units. J. of Fund. and Appl. Sci., 10, 1464-1481 (2018)

14. O.G. Degtyareva, D.A. Dac'o, G.V. Degtyarev, A.D. Gumbarov. Design in cae system of low-head weir tiled foundation sinking. Proc. of the Kuban State Agrar. Univ., 64, 221-226 (2017)

15. L.V. Kireicheva, N.P. Karpenko. Evaluation of the efficiency of irrigation in a zonal soil sequence. Euras. soil sci., 48(5), 524-532 (2015)

16. L.V. Kirejcheva et al. New technologies for designing, substantiating the construction, operation and management of land reclamation systems (Publ. House of GNU VNIIA Rus. Agricult. Acad., Moscow, 2010), $240 \mathrm{p}$

17. O.G. Degtyareva, G.V. Degtyarev, N.L. Lavrov, D.U. Aliev. Constructive-technological decisions in 
regulating the flow of atmospheric precipitation. Magaz. of Civil Eng., 82(6), 32-48 (2018)

18. M.A. Bandurin, V.A. Volosukhin, A.V. Mikheev, Ya.V. Volosukhin, I.P. Bandurina. Finite element simulation of cracks formation in parabolic flume above fixed service live. IOP Conf. Ser. Mat. Sci. and Eng., 327, 022010 (2018)

19. L.V. Kireicheva, F. Yurchenko, V.M. Yashin. Scientific principles of creation and management of reclamation systems in Russia (All-Rus. Res. Inst. of Agrochem., Moscow, 2017), 295 p

20. O.G. Degtyareva, T.I. Safronova, I.I. Rudchenko, I.A. Prikhodko. Nonlinearity account in the foundation soils when calculating the piled rafts of buildings and constructions. IOP Conf. Ser. Mat. Sci. and Eng. 698(2) (2019)

21. O. Degtyareva, G. Degtyarev, I. Togo, V. Terleev, A. Nikonorov, Yu. Volkova. Analysis of stressstrain state rainfall runoff control system - buttress dam. Proc. Eng., 165, 1619-1628 (2016)

22. V.G. Degtyarev, N.V. Kozhenko. Consolidation processes in clay soils, taking into account the multistory building construction staging. IOP Conf. Ser. Mat. Sci. and Eng., 698(2), 022016 (2019) 